UNIVERSITA
DEGLISTUDI
DI TORINO

\title{
THE IMPACT OF SICKNESS ABSENTEEISM ON PRODUCTIVITY: NEW EVIDENCE FROM BELGIAN MATCHED PANEL DATA
}

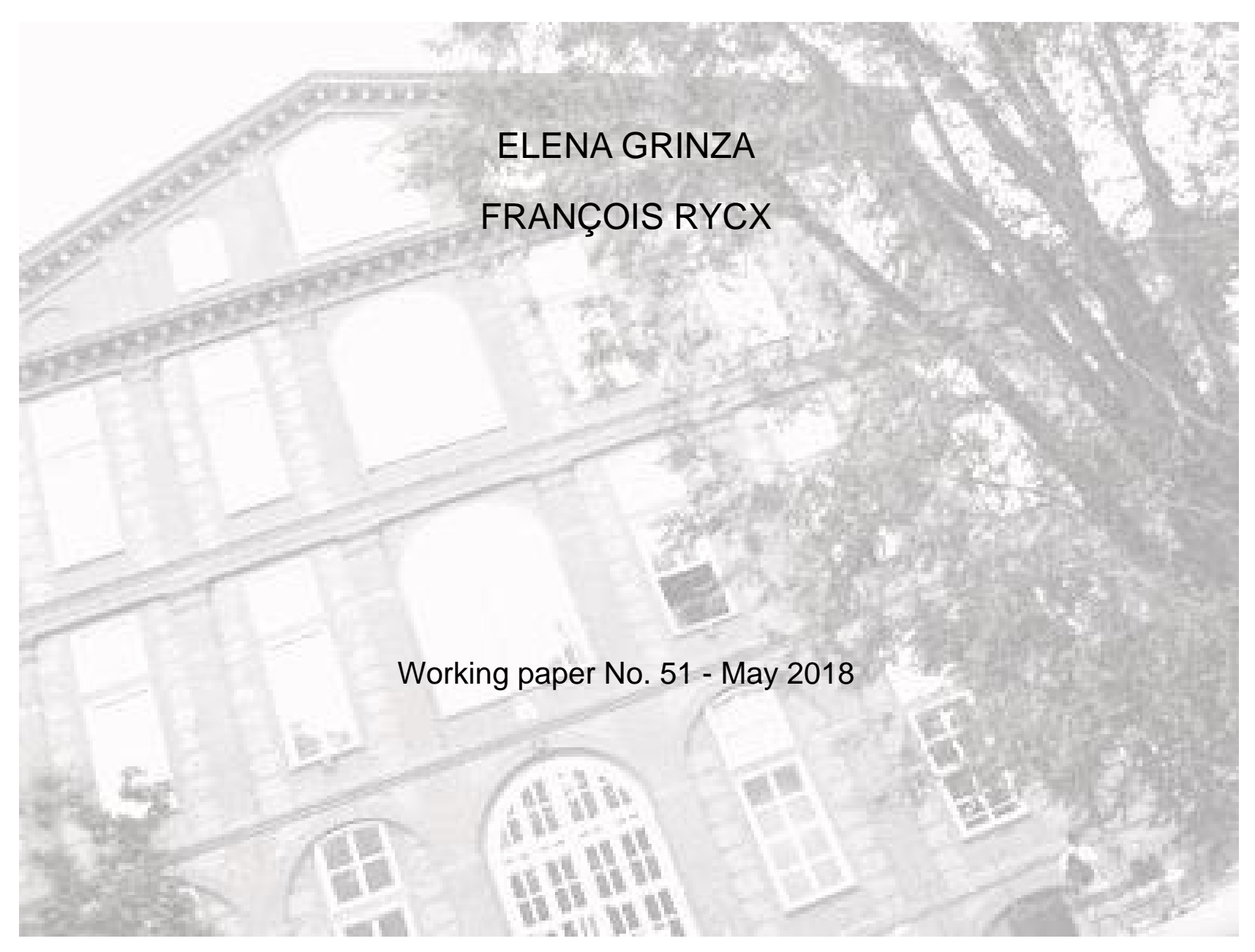




\title{
The Impact of Sickness Absenteeism on Productivity: New Evidence from Belgian Matched Panel Data
}

\author{
Elena Grinza ${ }^{\mathrm{a}, *}$, François Rycx ${ }^{\mathrm{b}}$ \\ ${ }^{a}$ University of Milan and University of Turin \\ ${ }^{b}$ Université Libre de Bruxelles, humanOrg, IRES, and IZA
}

\begin{abstract}
We investigate the impact of sickness absenteeism on productivity by using rich longitudinal matched employer-employee data on Belgian private firms. We deal with endogeneity, which arises from unobserved firm heterogeneity and reverse causality, by applying a modified version of the Ackerberg et al's (2015) control function method, which explicitly removes firm fixed effects. Our main finding is that, in general, sickness absenteeism substantially dampens firm productivity. An increase of 1 percentage point in the rate of sickness absenteeism entails a productivity loss of $0.24 \%$. Yet, we find that the impact is much diversified depending on the categories of workers who are absent and across different types of firms. Our results show that sickness absenteeism is detrimental mainly when absent workers are high-tenure or blue-collar workers. Moreover, they show that sickness absenteeism is harmful mostly to industrial firms, high capital-intensive companies, and small- and medium-sized enterprises. This overall picture is coherent with the idea that sickness absenteeism is problematic when absent workers embed high levels of firm/task-specific (tacit) knowledge, when the work of absent employees is highly interconnected with the work of other employees (e.g., along the assembly line), and when firms face more limitations in substituting temporarily absent workers.

Keywords: Sickness absenteeism, firm productivity, semiparametric methods for estimating production functions, longitudinal matched employer-employee data.
\end{abstract}

JEL: D24, M59, I15

${ }^{*}$ Corresponding author: elena.grinza@unimi.it; elena.grinza@unito.it. 


\section{Introduction}

According to the World Health Organization (WHO), in the EU-15, in 2013, an average of 10.9 days of work per employee were lost due to sickness absence. While a fast search on the Internet shows that both policy makers and managers widely believe that sickness absenteeism imposes a considerable cost to advanced industrialized economies, there is a surprising lack of studies which assess the magnitude and nature of such cost, particularly concerning productivity-related effects.

We provide new evidence on this by exploring the impact of sickness absenteeism on firm productivity. We focus on productivity because the literature on this is extremely scarce. At the same time, productivity growth is a well-known key determinant of sustained and sustainable economic growth. Therefore, understanding which factors and how they influence productivity is an important task for research. In recent years, a small but compelling line of literature is deepening our knowledge on the productivity impact of several labor-related issues (e.g., Devicienti et al., 2018; Giuliano et al., 2017; Vandenberghe, 2012), and this paper intends to enrich it with new results.

Our aims (and main contributions to the literature) are twofold. First, we seek to obtain a consistent estimate of the productivity impact of sickness absenteeism and, hence, to reliably assess the magnitude of the impact. Second, we aim to understand whether and how the impact of sickness absenteeism on productivity depends on several workforce and firm characteristics that may be relevant, such as the categories of workers who are absent and the firm's industry, type of technology, and size.

We perform our empirical analysis by resorting to rich matched employer-employee data on Belgian private firms over the period 1999-2007. Thanks to detailed information on each employee's worked and non-worked hours, we are able to construct a measure of the firm's rate of sickness absenteeism. The unique feature of our data is that we are able to isolate absenteeism certainly due to sickness from that stemming from other reasons (e.g., educational leave and other personal leaves). However, due to data limitations, we are forced to concentrate on short-term sickness absenteeism, which nonetheless constitutes a substantial fraction of total sickness absenteeism. Moreover, the matched employer-employee nature of our data allows us to compute rates of sickness absenteeism that are specific to several categories of workers (e.g., blue-collar versus white-collar workers). We take care of endogeneity due to unobserved firm heterogeneity and reverse causality by adopting a modified version of the Ackerberg et al's (2015) control function approach, developed by Vandenberghe et al. (2013), which explicitly removes firm fixed effects.

Consistently with common beliefs, our main finding is that sickness absenteeism is, in general, significantly detrimental to firm productivity. The magnitude of the impact is large. 
According to our estimates, an increase of 1 percentage point in the rate of sickness absenteeism entails a productivity loss of $0.24 \%$. Firm productivity may suffer for several reasons. Finding temporary substitute workers up to par with absent workers may be difficult if absent workers have high levels of firm/task-specific (tacit) knowledge. The absence of workers can slow down the work of other employees. It can also create organizational problems if other employees find it hard to cope up with the work that is usually done by absent workers.

To have a better understanding of the mechanisms at play, we embark on a moderator analysis. We find that the effect of sickness absenteeism is much diversified across categories of workers. The impact is large and significant when high-tenure workers are those absent, while it is (positive) small and not significant for low-tenure workers. The same happens when we look at occupations: the impact of sickness absenteeism of blue-collar workers is large and significant, while the impact for white-collar workers is small and not significant. We find that the impact substantially differs across firms, too. If industrial firms, high capital-intensive companies, and small- and medium-sized enterprises suffer much from sickness absenteeism, the impact on non-industrial firms, low capital-intensive companies, and big enterprises is (sometimes positive) small and not significant. These results are coherent with the idea that sickness absenteeism represents a real threat for firms only under definite circumstances: when absent workers embed substantial amounts of firm/task-specific (tacit) knowledge, when workers are highly interconnected (e.g., along the assembly line or in case of teamwork), and when optimal staffing is more problematic to achieve when there are absent workers or hiring temporary substitute workers is more difficult.

Our results have pervasive policy implications. In short, they urge both policy makers and managers to invest more in employees' health, particularly for those workers and in those firms for which sickness absenteeism is disruptive. Most importantly, investing more in employees' health can represent a win-win strategy: employees could benefit from improved health and firms could benefit from productivity gains due to reduced sickness absence.

The rest of the paper is structured as follows. Section 2 discusses the theoretical mechanisms behind the impact and presents a literature review of previous empirical works. Section 3 presents our empirical model and discusses the main endogeneity issues and the method adopted to address them. Section 4 presents institutional details and statistics for Belgium. Section 5 describes the data and shows relevant sample descriptive statistics. Section 6 presents and discusses our results. Section 7 concludes and draws policy implications.

\section{Literature review}

Sickness absenteeism is costly. The seminal paper by Steven G. Allen synthesizes the main effects it has on firms, and this review of the theoretical channels largely builds on his work (Allen, 1983). 
Sickness absenteeism directly affects the firm's labor costs. In most countries, firms have to pay (at least partially) their workers while they are absent. If firms want to get the work of absent workers done, they either need to pay overtime hours to other workers or hire temporary substitute workers. If firms choose the latter alternative, they likely bear other costs, such as those related to recruitment and training. Sickness absenteeism may also have indirect effects that increase labor costs. Higher wages may be the price to gain workers' adhesion to stricter sickness absenteeism provisions.

Apart from these negative effects on the firm's total wage bill, sickness absenteeism also imposes losses on productivity. If firms choose not to resort to overtime or temporary substitute workers, they experiment a loss of output at least equal to the output produced by absent workers. This output loss becomes heavier if absent workers perform a work that is highly interconnected with the work of other employees (see also Pauly et al., 2002). In this case, workers' absence not only causes the loss of output produced by absent workers, but also entails productivity losses of other workers, which may take place in the form of organizational problems, information inefficiencies, and transaction costs. A case in point is assembly line production, in which the tasks of different employees are deeply interconnected (Coles et al., 2007). Other examples include teamwork in teams with expanded decision-making and responsibility, such as in project management teams (Heywood et al., 2008).

Even if overtime or temporary substitute workers perform the work of absent workers, productivity losses likely occur. Overtime or temporary substitute workers may have lower productivity compared to absent workers. This is an especially critical point if absent workers have high levels of firm/task-specific knowledge, which makes it difficult to temporarily replace them easily (see also Pauly et al., 2002). If tacit knowledge of absent workers about the firm and tasks' processes and routines is deep, productivity losses likely become heavier, as tacit knowledge resides in the mind of absent workers and cannot be formalized or transferred to others (Grant, 1996; Nonaka, 1994). In addition, if the work of absent employees is highly interconnected with the work of other employees, the reduced productivity of overtime or temporary substitute workers slows down the work of other employees.

Furthermore, staffing employees to perform the work of absent employees may not be easy. At the same time, temporary substitute workers may be difficult to find in a short time, thus causing organizational problems which dampen productivity. This is likely particularly relevant for small- and medium-sized enterprises since it may be more difficult for other employees to do the work of absent workers for such firms, and recruitment processes may not be as efficient and fast as in bigger firms (Pauly et al., 2002).

Yet, a zero rate of sickness absenteeism may not be an optimal (and realistic) goal for firms (Pauly et al., 2008). A zero level of sickness absence comes with a downside: presenteeism, that is, going to work while sick. Presenteeism could have negative effects, too. For example, sick 
workers might not be as productive as usual and cause other negative effects (e.g., employees with the flu or flu symptoms may be contagious). In such cases, it may be more efficient if sick workers stay home and heal completely.

In sum, it appears that reducing sickness absenteeism is an important goal for firms (and societies). However, this goal should not be achieved by increasing presenteeism, but by effectively improving employees' health.

From our theoretical discussion, we can draw a set of four hypotheses concerning the impact of sickness absenteeism on productivity, which we will test in our empirical analysis.

Hypothesis 1: The impact of sickness absenteeism on productivity is negative.

Hypothesis 2: The impact of sickness absenteeism on productivity is stronger when absent workers have high levels of firm/task-specific (tacit) knowledge.

Hypothesis 3: The impact of sickness absenteeism on productivity is stronger when the work of absent employees is highly interconnected with the work of other employees (e.g., along the assembly line).

Hypothesis 4: The impact of sickness absenteeism on productivity is stronger in small- and medium-sized enterprises.

Very few empirical studies explore the impact of absenteeism on productivity and, to the best of our knowledge, no study specifically focuses on sickness absenteeism. ${ }^{1}$ Allen (1983) uses US plant-level data matched with information on absenteeism rates at the industry level and OLS estimations, and finds a negative and significant, yet small, relation with productivity. More recently, Zhang et al. (2017) focus on Canadian panel data and find that absenteeism is significantly associated with lower productivity. They also report that this association gets higher in smaller firms and in the case of teamwork. Herrmann and Rockoff (2012) and Miller et al. (2008) find negative and significant relations between absenteeism and productivity, too. However, their studies focus on teachers, and their results are thus not directly transferable to the whole private sector.

Our paper contributes to this very limited empirical literature in several ways. First, as far as we know, it represents the first analysis that isolates the impact of sickness absenteeism from absenteeism due to other reasons not related to sickness, such as education leave or marriage. Indeed, these types of absences are radically different in nature from sickness absence, for

\footnotetext{
${ }^{1}$ Instead, there is a long tradition in the literature assessing the determinants of sickness absenteeism (e.g., Dionne and Dostie, 2007; Ichino and Riphahn, 2005; Markussen et al., 2011). There is also a relatively welldeveloped line of research investigating the impact of absenteeism on the firm's total wage bill, financial performance, or monitoring costs (see Allen, 1983; Coles et al., 2007; Heywood et al., 2008; Nicholson et al., 2006; Zhang et al., 2017).
} 
one thing, because they are generally known to firms well in advance. Moreover, they have different theoretical implications compared to sickness absence, which can significantly confound the results. For instance, firms with relatively more liberal policies on personal leaves may experiment productivity improvements because more employee-friendly work environments may contribute to enhance workers' morale, loyalty, and productivity. Second, our study employs state-of-the-art methods to deal with endogeneity. As we will discuss later, unobserved firm heterogeneity and reverse causality likely play crucial roles in this context. Therefore, properly addressing these issues is a crucial task, often overlooked by previous studies, which allows getting a more reliable estimate of the impact of interest. Third, our paper helps to better assess under which conditions sickness absenteeism is more problematic. This allows deepening our understanding of the mechanisms at stake and having a broader picture of the impact, which is important to give more informed policy advice.

\section{Empirical model and identification}

To explore the effect of sickness absenteeism on productivity, we resort to the following valueadded Cobb-Douglas production function:

$$
Y_{i t}=A_{i t} L_{i t}^{\beta_{l}} K_{i t}^{\beta_{k}}
$$

where $Y_{i t}, L_{i t}$, and $K_{i t}$ stand for, respectively, value added and (effective) labor and capital usage of firm $i$ at time $t$. We express $A_{i t}$, the total factor productivity (TFP) of firm $i$ at time $t$, as follows:

$$
A_{i t}=\exp \left\{\alpha+\theta S A B S_{i t}+\gamma F_{i t}+u_{i t}\right\}
$$

The term $\alpha$ is the average productivity of firms. The coefficient $\theta$ is our object of interest and measures the impact of sickness absenteeism $\left(S A B S_{i t}\right)$ on productivity. The term $F_{i t}$ is a vector of workforce and firm characteristics, which possibly influence productivity and sickness absenteeism. ${ }^{2}$ Finally, $u_{i t}$ is the error term. In other words, it is the productivity level of firm $i$ at time $t$ that is left unexplained. We decompose it into two parts. The first, $\omega_{i t}$, is the firm's productivity level at $t$ that is not observed by the econometrician, but is partly anticipated at $t-1$ and observed at $t$ by the firm. The second, $\epsilon_{i t}$, is an idiosyncratic error term uncorrelated with regressors.

We then use Equation (2) and take logs in Equation (1), and obtain the following estimating regression:

$$
y_{i t}=\alpha+\beta_{l} l_{i t}+\beta_{k} k_{i t}+\theta S A B S_{i t}+\gamma F_{i t}+\omega_{i t}+\epsilon_{i t},
$$

\footnotetext{
${ }^{2}$ We assume that these variables are exogenous.
} 
where lowercase letters indicate natural logarithms.

As our first aim is to assess if and how much sickness absenteeism dampens firm productivity, it is essential to consistently estimate $\theta$. To do this, the empirical analysis needs to address several endogeneity problems.

The first problem is commonly known as 'simultaneity of inputs'. It relates to the fact that inputs are endogenous since they respond to the firm's productivity level. For instance, firms that are highly productive will be willing to produce more, thus using more inputs. Likewise, productivity enhancements (e.g., thanks to the introduction of new process technologies) will raise the usage of inputs. This makes inputs correlated with $\omega_{i t}$.

The second issue, specific to our study, is that sickness absenteeism is endogenous, too. First, there is an omitted variable bias: some firm characteristics, unobserved by the econometrician, influence both productivity and sickness absenteeism. An example is represented by the firm's management quality. Good managers may take more care of their employees' health and invest more in employee-friendly work environments (e.g., which aim to limit workers' stress during work), thus achieving lower levels of sickness absenteeism. At the same time, good managers likely reach higher productivity levels also thanks to measures different from those related to enhancing workers' health. A similar bias may also emerge due to other unobserved firm characteristics that can impact on both productivity and sickness absenteeism, such as the degree of competition that the firm faces or its involvement in foreign markets. This makes sickness absenteeism correlated with $\omega_{i t}$. Second, there is a problem of reverse causality if sickness absenteeism affects productivity and, at the same time, it is influenced by productivity. This may happen when productivity/demand booms require employees to work more intensely, which may negatively affect their health and increase sickness absenteeism (e.g., workers may be subjected to increased stress from work). It may also happen that periods of economic downturns or productivity troubles negatively impact on workers' health and sickness absenteeism (e.g., workers may be more exposed to psychological sufferings such as anxiety and depression). Again, this makes sickness absenteeism correlated with $\omega_{i t}$.

Due to these endogeneity problems, ordinary least squares (OLS) estimation cannot consistently estimate $\theta$ (and the input elasticities, $\beta_{l}$ and $\beta_{k}$ ). Fixed effects (FE) estimation cannot either, despite it removes the time-invariant firm-specific productivity level. It would deliver consistent estimates only under two rather improbable circumstances: i) if the omitted variable bias derives exclusively from unobserved time-invariant variables, and ii) if inputs and sickness absenteeism do not respond to time-varying unobserved (by the econometrician) productivity levels. Hence, we need an estimation strategy that is able to account for a more realistic picture. The control function approach proposed by Ackerberg et al. (2015) (ACF, from now on) refines the methods developed by Olley and Pakes (1996) and Levinsohn and Petrin (2003), and represents a solution to endogeneity. In practice, ACF use the firm's demand for intermediate 
inputs to proxy for the unobserved productivity level $\omega_{i t}$. The rationale is that intermediate inputs are able to capture the firm's unobserved productivity level. This is because firms can relatively easily adjust their use of intermediate inputs in response to productivity shocks. In this study, we adopt a modified version of the ACF procedure, developed by Vandenberghe et al. (2013) (ACF-FE, from now on). The ACF-FE method extends the ACF procedure by explicitly accounting for and removing firm fixed effects. This ensures that unobserved fixed firm heterogeneity is eliminated. It also improves the ability of the proxy to capture the (fluctuations in the) unobserved productivity level. Appendix A provides a detailed description of our empirical framework and illustrates the ACF and ACF-FE methods.

\section{The Belgian case}

Belgium has rather protective labor laws concerning sick pay. This makes the level of Belgian sickness protection comparable to that of many other European countries, including Germany, France, Italy, and Nordic countries.

In some states, the law mandates that employers must cover workers' pay while they are out sick. Other countries operate instead social insurance systems, where the government provides sick pay. As most European countries such as Germany, Spain, and Nordic countries, Belgium adopts a mix of employer mandates and social insurance system to provide sick pay.

In Belgium, employees have the right to receive their normal salary during a period of 30 calendar days in the case of absence due to sickness (or injury). This is the so-called 'salaire garanti' rule (i.e., 'guaranteed salary' rule). To be entitled to the guaranteed salary, employees need to comply with some legal obligations, including, for example, immediately informing the employer of their sickness status and presenting a medical certificate.

Belgium has two sets of provisions for sick pay: one specific to white-collar workers and one to blue-collar workers. Employers must pay the full wage (i.e., 100\%) during the whole 30 calendar days of guaranteed salary for white-collar workers. For blue-collar workers, instead, employers must pay $100 \%$ of the wage during the first 7 days of absence from work, except for the first day, which is not paid at all. ${ }^{3}$ From the 8 th to the 14 th day of sickness absence, employers must cover only $85.88 \%$ of the wage. From the 15 th to the 30 th day of sickness absence, employers must cover only $25.88 \%$ of the wage for the amount below a certain threshold and $85.88 \%$ for the amount above that threshold. The social security covers the rest so as to guarantee workers' wage between day 1 (2, if there is the 'jour de carence') and 30.

During the first year of absence following the period covered by the guaranteed salary,

\footnotetext{
${ }^{3}$ This is known as 'jour de carence'. The 'jour de carence' was suppressed in 2014. The first day of sickness absence is now fully paid by employers also for blue-collar workers. Yet, as our data cover the period 1999-2007, the 'jour de carence' was still applicable.
} 
employees receive sick pay from the social security. These benefits equal $60 \%$ of employees' gross capped wage. Employees that continue to be sick in the second year, are entitled to invalidity benefits if a specific board confirms the invalidity.

As for the level of sickness absence in Belgium, WHO estimates that, on average, Belgian employees were absent from work due to sickness for a total of 11.2 days in 2013, a level comparable to the EU-15 average (10.9). This means that, in Belgium, in 2013, 5.2\% of total annual working days went lost due to sickness absence.

\section{Data and measurement}

We perform our empirical analysis on a combination of two large data sources covering the period 1999-2007.

The first data set, provided by Statistics Belgium, is the Structure of Earnings Survey (SES). It collects a sample of firms that operate in Belgium, employ at least 10 workers, and belong to sectors within sections $\mathrm{C}$ to $\mathrm{K}$ of the NACE Rev. 1 (statistical classification of economic activities in the European Community). ${ }^{4}$ The SES data set contains a wealth of information, provided by the human resources departments of firms, on the characteristics of the firm (e.g., sector of economic activity, number of workers, level of collective wage bargaining) and employees working in the firm (e.g., gender, age, education, tenure, occupation, and hours worked and not worked). These features make SES a matched employer-employee data set. ${ }^{5}$

The SES data set does not provide financial information on firms. To obtain this source of information, which is necessary for estimating our augmented production function, SES is matched with a different firm-level survey, the Structure of Business Survey (SBS). It is also conducted by Statistics Belgium and provides information on several financial variables, including value added, value of investments in tangible fixed assets, and expenditure on intermediate

\footnotetext{
${ }^{4}$ The SES data set thus covers the following sectors: mining and quarrying (C); manufacturing (D); electricity, gas, and water supply (E); construction (F); wholesale and retail trade, and repair of motor vehicles, motorcycles, and personal and household goods $(\mathrm{G})$; hotels and restaurants $(\mathrm{H})$; transport, storage, and communication (I); financial intermediation $(\mathrm{J})$; real estate, renting, and business activities $(\mathrm{K})$.

${ }^{5}$ The SES data set is the result of a complex stratified sampling design. The stratification criteria refer to the region (NUTS-groups), sector of economic activity (NACE-groups), and firm size. The sample size in each stratum depends on firm size. Sampling percentages of firms are equal to 10, 50, and $100 \%$ when the number of workers is, respectively, lower than 50, between 50 and 99 , and above 100. Within the firm, sampling percentages of employees also depend on firm size. Sampling percentages of employees reach 100, 50, 25, 14.3, and $10 \%$ when the number of workers is, respectively, lower than 20, between 20 and 50, between 50 and 99, between 100 and 199, and between 200 and 299. Firms that employ 300 workers or more have to report information for a specific number of employees. This number ranges between 30 (for firms with between 300 and 349 workers) and 200 (for firms with 12,000 workers or more). To ensure that firms report information on a representative sample of their workers, they are asked to follow a specific procedure. For a more detailed discussion, see Demunter (2000).
} 
inputs. ${ }^{6}$ Statistics Belgium carried out the match between the SES and SBS data sets by using the firm's social security number as firm identifier. We will refer to the resulting matched employer-employee panel data set as 'SES-SBS'.

In the empirical analysis, we measure output with (deflated) value added. We measure labor with the total number of hours worked (including overtime hours). ${ }^{7}$ We compute capital from flows of (deflated) value of investments in tangible fixed assets, by applying a version of the perpetual inventory method described in OECD (2009). It rests on the idea that capital results from investment flows after correction for retirement and efficiency loss. Following the standard practice, we assume a $5 \%$ annual rate of depreciation of capital. We measure intermediate inputs, used in the ACF and ACF-FE procedures to proxy the firm's unobserved productivity level, with the (deflated) expenditure on raw materials, consumables, commodities, services, and other ancillary costs.

The SES data set provides detailed information on the number of hours not worked, divided into three categories. The first is the number of hours paid by the firm but not worked due to sickness (or injury). The second is the number of hours paid by the firm but not worked due to reasons other than sickness, such as holidays for employees, compulsory medical examinations, public holidays, pregnancy tests, absence due to wedding or death of a close family member, etc. The third is the number of hours that are not worked and not paid (or only partially paid) by the firm. This category is heterogeneous and includes the 'jour de carence' for blue-collar workers, hours lost by white-collar workers absent due to sickness beyond 30 days, hours lost by blue-collar workers absent due to sickness beyond 7 days, hours lost by employees on sabbatical leave and women on maternity leave (in Belgium, maternity leave is entirely paid by the social security from day 1 on).

To compute sickness absenteeism, we rely on the first category: the number of hours paid by the firm but not worked due to sickness. In practice, the rate of sickness absenteeism, our regressor of interest, is obtained by dividing the number of hours paid by the firm but not worked due to sickness by the total number of hours worked. In this way, differently from previous empirical works, we are able to isolate absence certainly due to sickness. Unfortunately, given the structure of our data set, we are not able to compute a total measure of sickness absenteeism. In fact, longer-term sickness absence is mixed with other kinds of absences that have nothing to do with sickness, such as maternity or sabbatical leave. Hence, our measure of sickness

\footnotetext{
${ }^{6}$ The SBS data set does not cover the whole financial sector (NACE J) as SES does, but only two of its subsectors: 'Other Financial Intermediation' (NACE 652) and 'Activities Auxiliary to Financial Intermediation' (NACE 67).

${ }^{7}$ The information on hours worked (and other workforce characteristics) reported in the SES data set refers to the month of October of any given year. We thus rely on the assumption that October represents a good proxy for the whole year. This is a common feature of matched employer-employee data sets (see, for instance, Mion and Opromolla, 2014).
} 
absenteeism should be considered as short-term. ${ }^{8}$

We conduct a basic cleaning of the original SES-SBS data set. First, we delete a few firms that are publicly controlled (i.e., for which public financial control exceeds 50\%). All regressions are therefore applied to privately controlled firms only. The rationale derives from the standard productivity theory and its requirement that prices have to be economically meaningful. We then exclude workers and firms for which information is missing, inaccurate, or unusable. To warrant that workforce-related variables (e.g., the share of females in the firm) are based on a sufficient number of observations, we eliminate a very small number of firms providing valid information on less than 10 employees. To ensure that financial information provided by SBS is at the same level of workforce-related information provided by SES, we also remove firms with multiple plants. Finally, we remove firms with less than three years of consecutive observations. To perform the ACF-FE (and ACF) estimations, we are forced to consider firms with at least two consecutive years of observations. Since the ACF-FE method is highly demanding in terms of data quality (e.g., it exploits only within-firm information), we require an additional year of observation to get more reliable and precise estimates. This restriction leads to the over-representation of medium- and large-sized firms. This is due to the fact that sampling percentages of firms in the SES data set increase with firm size (see Footnote 5). In conclusion, our final data set is representative of Belgian single-plant and medium- and large-sized firms that operate in the private sector, with the exception of a large part of the financial sector (NACE J). ${ }^{9}$

Our final sample consists of an unbalanced panel of 5,319 observations for 1,107 firms. Table 1 shows that half of these firms are observed at least for four consecutive periods, and $11.3 \%$ of them are observed over all our observation windows (9 years). Table 2 shows that a few firms belong to the mining and quarrying sector $(0.8 \%)$, most to the manufacturing industry $(61.0 \%)$, and about one in ten to the construction industry $(11.3 \%)$. The remaining fraction of firms is split between the trade (9.6\%) and services (17.4\%) industries. ${ }^{10}$ Most of the firms in our sample are medium-sized or big: $52.9 \%$ of them employ between 50 and 249 workers and $29.9 \%$ of them employ 250 or more workers, while only $17.2 \%$ employ less than 50 workers. Table 3 reports some descriptive statistics of our sample. On average, firms employ about 243 workers, produce a value added of slightly more than 20.7 million Euros per year and a gross operating margin of about 8.3 million Euros per year. On average, females represent about $23.6 \%$ of the workforce; about three-quarters of the workers do not hold tertiary education, and

\footnotetext{
${ }^{8}$ Finally, to compute the proportion of workers by gender, age, etc., we divide the total number of hours worked by each category of workers by the total number of hours worked in the firm.

${ }^{9}$ Note that we experimented regressions also including firms with multiple plants and/or firms observed for only two consecutive years, and obtained a broadly consistent picture.

${ }^{10}$ For simplicity, we often say 'firms' actually meaning '(firm-year) observations', as in this case.
} 
the great majority of them $(62.2 \%)$ have between 30 and 49 years of age. On average, the vast majority $(79.2 \%)$ of the workers work in the same firm since at least 10 years; about one worker in ten is a part-timer, and a few workers (4\%) have temporary contracts. On average, most of the employees $(59.3 \%)$ are blue-collar workers, such as craft workers or plant and machine operators. The remaining fraction of workers (40.7\%) constitutes white-collar workers: most of them are clerks, professionals, or technicians, while a few have managerial duties.

Table 4 shows descriptive statistics on sickness absenteeism. On average, in our sample, 2.1\% of total hours worked are lost due to short-term sickness absenteeism. This level represents about half of the rate of total sickness absenteeism provided by the official statistics, which suggests that short-term sickness absenteeism constitutes a substantial part of total sickness absenteeism. ${ }^{11}$ On average, blue-collar workers are more absent due to sickness (twice as much) than white-collar workers, consistently with the idea that blue-collar workers are more subject to injuries and work-related pathology compared to white-collar workers. There is no substantial difference in absenteeism rates of high- compared to low-tenure workers. Finally, we observe approximately the same degrees of sickness absenteeism across the categories of firms that we will analyze separately (see Subsection 6.2), namely, industrial versus non-industrial firms, low versus high capital-intensive firms, and small- and medium-sized versus big firms. In all these categories of firms, sickness absenteeism rate oscillates around 0.020 and 0.021 , values near to the overall average.

\section{Results}

\subsection{The overall impact of sickness absenteeism on productivity}

In this section, we present our results on the overall impact of sickness absenteeism on productivity. In Table 5, we show the OLS, FE, ACF, and ACF-FE estimates of the impact. As discussed in Section 3, our preferred method is ACF-FE. In all these (and the following) estimations, we control for a large set of workforce and firm characteristics. Our control variables include the proportions of the firm's workforce by gender, age, education, occupation, duration of the work contract (i.e, open-end versus fixed-term), working time arrangement (i.e., parttime versus full-time), and tenure in the firm. They also include dummy indicators for the level of collective wage bargaining and the firm's age. Finally, they comprise dummies for the firm's size, region, and industry, and time dummies. The FE and ACF-FE estimations also remove

\footnotetext{
${ }^{11}$ This is not an exact comparison as we compute sickness absenteeism at the firm-level and as a percentage of hours lost due to sickness over the total hours worked in the firm, including regular and overtime hours. Differently, official statistics provide a measure of sickness absence on an individual-level and as a percentage of days of absence over the theoretical working days.
} 
firm fixed effects. ${ }^{12}$ All standard errors are robust to heteroskedasticity since we compute robust standard errors in the OLS and FE estimations and bootstrap standard errors in the ACF and ACF-FE estimations.

According to the OLS estimates, the impact of sickness absenteeism on productivity is negative, but not significant. We know, however, that OLS estimation suffers from a variety of endogeneity problems, which likely hinder the identification of the impact. For example, unobserved characteristics of the firm, such as management quality, may contribute to confounding the estimation. Also, periods of crisis/booms may influence the level of sickness absenteeism. FE estimation partially addresses such types of problems since it removes unobserved timeinvariant heterogeneity (i.e., it accounts for firm fixed effects). According to the more robust FE estimation, the impact of sickness absenteeism is negative and significant, as our first hypothesis predicts (see Hypothesis 1). Yet, FE estimation delivers a consistent estimate of the impact only under very strict assumptions, which are rather unrealistic. For example, for FE estimation to give a consistent estimate of the impact, it should hold that sickness absenteeism (and inputs) does not respond to fluctuations in the firm's productivity level. ACF estimation accounts for a more articulated and realistic picture, according to which inputs and sickness absenteeism can respond to productivity fluctuations (and omitted variable bias can stem from time-varying variables). The ACF estimate of the impact of sickness absenteeism is again negative, similar to the FE estimate, and significant. This further confirms our hypothesis that sickness absenteeism is significantly detrimental to productivity.

The last column of Table 5 reports the ACF-FE estimates. ACF-FE estimation potentiates the ACF procedure by explicitly removing firm fixed effects. Apart from ensuring that unobserved fixed firm heterogeneity is removed, it also improves the ability of the ACF method to capture the firm's unobserved productivity level. Our ACF-FE estimates confirm that the impact of sickness absenteeism on productivity is negative and significant. They also indicate that the impact is large. A 1 percentage point increase in the rate of sickness absenteeism is estimated to decrease productivity by as much as $0.24 \%$ (i.e., $\left.\left(\exp ^{-0.236 * 0.010}-1\right) * 100\right) .{ }^{13}$

Summarizing, up to now we found that sickness absenteeism is, in general, significantly detrimental to firm productivity and that the impact is considerably large in magnitude.

\footnotetext{
${ }^{12}$ When estimations account for firm fixed effects, we do not include region and industry dummies as they do not vary over time.

${ }^{13}$ The ACF-FE estimates of labor and capital elasticities are 0.794 and 0.195 , respectively. Such values are comparable to those found by the literature on the estimation of value-added production functions (see, for example, Van Biesebroeck, 2007). Both estimates are significantly different from zero at any conventional level.
} 


\subsection{The diversified impacts of sickness absenteeism on productivity: the role of workforce and} firm characteristics

Apart from the basic hypothesis that sickness absenteeism dampens firm productivity, in Section 3 we formulated three additional hypotheses, according to which the impact of sickness absenteeism exacerbates when three circumstances occur. In this subsection, we aim to verify each of them.

According to Hypothesis 2, the impact of sickness absenteeism is stronger when absent workers have high levels of firm/task-specific (tacit) knowledge. To assess whether this happens, we resort to the information provided in the SES data set on workers' tenure, that is, since how long they are working in the firm. Tenure represents a natural proxy for the level of firm/task specific (tacit) knowledge accumulated by workers. This is based on the simple idea that workers who are working in the firm since much time have a deeper knowledge about the firm and tasks' processes and routines compared to workers who are working in the firm since relatively less time. In particular, we compute the rate of sickness absenteeism among workers with high tenure (10 years or more of tenure) and workers with low tenure (less than 10 years of tenure). The first panel of Table 6 reports results for this. According to the ACF-FE estimates ${ }^{14}$, sickness absenteeism is significantly and highly detrimental (-0.479 is the point estimate) when absent workers are those with high tenure. Conversely, when absent workers are those with low tenure, the impact on productivity is (positive) small (0.006) and not significant. This result validates Hypothesis 2 and is coherent with the idea that sickness absence is especially problematic when the level of (tacit) knowledge about the firm and tasks' processes and routines is deep, which makes it difficult for the firm to find adequate substitutes, at least in the short-run. On the contrary, our results are in line with the idea that when absent workers have lower knowledge about the firm and/or tasks performed, they can be replaced with substitute workers more easily, thus preventing from significant and large drops in productivity.

According to Hypothesis 3, sickness absenteeism is more detrimental when the work of absent workers is highly interconnected with the work of other workers. A case in point is assembly line production. Unfortunately, we do not have direct information on whether the firm has an assembly line production type. Yet, we can pinpoint such firms indirectly. To this end, we exploit information on the workers' occupation, firm's sector, and firm's capital intensity. Firms with assembly line production are generally industrial firms (i.e., they produce tangible goods) and high capital-intensive firms (i.e., there are production plants equipped with machinery), and workers in the assembly line are blue-collar workers. We define industrial firms as firms belonging to the following sectors: mining and quarrying, manufacturing, and construction. Conversely, non-industrial firms include firms in the trade and services sectors. Moreover, we

\footnotetext{
${ }^{14}$ From now on, we only report the ACF-FE results, as ACF-FE is our preferred method.
} 
classify low and high capital-intensive firms as those whose ratio between capital and labor (expressed in full-time equivalent employees) is below (above) the median. Finally, we compute the rate of sickness absenteeism among white- and blue-collar workers. The second panel of Table 6 shows that the impact of sickness absenteeism is negative (-0.247) and significant only when blue-collar workers are those absent, while it is small (-0.022) and not significant when white-collar workers are those absent. The first panel of Table 7 shows that the impact is negative (-0.288) and significant only for industrial firms, whereas, for non-industrial firms, it is small (-0.026) and not significant. The second panel of Table 7 shows that the impact is negative, very large (-0.683), and significant only for high capital-intensive firms. Conversely, for low capital-intensive firms, the impact of sickness absenteeism is (positive) small (0.057) and not significant. Summarizing, we find that sickness absenteeism is significantly (and largely) detrimental only when blue-collar workers are those absent, in industrial firms, and in high capital-intensive firms, which are all situations coherent with an assembly line production type.

Finally, Hypothesis 4 predicts that sickness absenteeism is particularly damaging for smalland medium-sized enterprises. The reason is that, for such firms, it is likely more difficult to staff other workers to perform the work of absent workers and/or to hire temporary substitute workers. We investigate whether this is the case by performing separate regressions on smalland medium-sized firms and big firms. Following the European Commission classification, we define small- and medium-sized firms as firms with less than 250 employees. Conversely, we define big firms as firms employing 250 workers or more. The results support our hypothesis. We find that the impact of sickness absenteeism is negative (-0.328) and significant for small- and medium-sized firms. Conversely, for big firms, it is (positive) small (0.001) and not significant.

\section{Conclusions}

In this paper, we explore the impact of sickness absenteeism on productivity. By using rich matched employer-employee data, we are among the first to investigate the productivity impact of absenteeism, and the first which specifically concentrate on sickness absenteeism. We carefully deal with endogeneity issues, which appear to be much problematic in this specific context, by using state-of-the-art econometric methods (i.e., ACF and ACF-FE).

Coherently with expectations of policy makers and managers, our results show that sickness absenteeism has a significant and large impact on productivity. In general, a 1 percentage point increase in the rate of sickness absenteeism is estimated to decrease productivity by as much as $0.24 \%$.

Yet, our results show that sickness absenteeism does not impact firms in the same manner regardless of workforce and firm characteristics. On the contrary, we found that the impact is much diversified along three main dimensions, in a way that is coherent with what one would reasonably expect. First, we found that the negative impact significantly and largely emerges 
only when high-tenure workers are those absent. This indicates that if absent workers have high levels of firm/task-specific (tacit) knowledge, it is problematic to find adequate substitutes and this causes large drops in productivity. Second, we found that the impact of sickness absenteeism is negative and significant only when blue-collar workers are those absent, and in the case of industrial firms and high capital-intensive firms. These are all situations that point to an assembly line production type. In fact, it is reasonable to expect that sickness absenteeism gets more problematic as the firm's production entails a higher degree of interconnection among workers. Third, our results show that the impact of sickness absenteeism on productivity is negative and significant only for small- and medium-sized enterprises. This is coherent with the idea that smaller firms generally have more difficulties to recruit in a short time temporary substitute workers and to optimally staff other workers to perform the work of absent workers (in the meantime).

The main policy implication of our finding is that sickness absenteeism not only imposes a direct cost on firms and societies (i.e., wage paid to workers while they are absent), already acknowledged by a large part of economic literature on absenteeism, but also, and possibly more importantly, it imposes a productivity loss on firms (and, on an aggregate basis, on the society). This finding reveals its importance if we consider that productivity growth is a well-known major source of sustained and sustainable economic growth. Policy makers should then invest more resources to improve workers' health. Their effort should concentrate on potentiating informative campaigns on healthy habits and plans for improving workers' wellbeing in the workplace and out. Yet, a fundamental role should be played by firms in the first place: they should invest more in enhancing their workers' well-being, for example by implementing structured wellness programs and providing higher-quality health insurance to their employees. Firms should also invest more in programs that improve the safety in the workplace since absence due to injuries on the job constitutes a considerable component of sickness absence. Similarly, firms should invest more in developing employee-friendly work environments, since absences due to stress and mental health problems related to work are known to be a major determinant of sickness absenteeism, too. In this light, firms' investments to ensure a better health to their employees operate as a win-win strategy. On the one hand, firms could benefit from reduced sickness absenteeism and avoid large productivity drops. On the other hand, employees could benefit from enhanced health, in the first place, and from higher wages due to the fact that firms would be more productive, in the second place.

Furthermore, our findings suggest that managers should consider investing more in their employees' well-being and on-the-job safety programs especially if they head up firms in which sickness absenteeism entails large productivity penalties. Such cases include having a substantial fraction of the workforce with a deep knowledge of the firm and tasks' practices and routines (i.e., with high tenure), heading up firms characterized by an assembly line production type (or, 
more generally, by team production), and heading up small- or medium-sized firms. Relatedly, policy makers could consider designing incentives in the promotion of wellness programs and health insurance specifically for these categories of workers/firms. 
Table 1: Distribution of firms by number of consecutive panel observations

\begin{tabular}{l|l|l}
\hline \hline Number of consecutive panel observations & Observations & Firms \\
\hline 3 & 1,344 & 448 \\
4 & 748 & 187 \\
5 & 760 & 152 \\
6 & 468 & 78 \\
7 & 434 & 62 \\
8 & 440 & 55 \\
9 & 1,125 & 125 \\
\hline Total & 5,319 & 1,107 \\
\hline \hline Source: SES-SBS data set (years: 1999-2007)
\end{tabular}

Source: SES-SBS data set (years: 1999-2007)

Table 2: Distribution of firms by industry and size

\begin{tabular}{l|l|l}
\hline \hline Industry & Observations & Percentage \\
\hline Mining and quarrying & 40 & 0.75 \\
Manufacturing & 3,243 & 60.97 \\
Construction & 602 & 11.32 \\
Trade & 508 & 9.55 \\
Services & 926 & 17.41 \\
\hline Total & 5,319 & 100 \\
\hline \hline Size & Observations & Percentage \\
\hline$[10-50)$ Employees & 917 & 17.24 \\
{$[50-250)$ Employees } & 2,812 & 52.87 \\
$\geq 250$ Employees & 1,590 & 29.89 \\
\hline Total & 5,319 & 100 \\
\hline Source: SES-SBS data set (years: 1999-2007)
\end{tabular}




\section{Table 3: Sample summary statistics: general information}

\begin{tabular}{|c|c|c|c|}
\hline Variable & Notes & Mean & Std. dev. \\
\hline Employees & Number of employees & 243.767 & 391.294 \\
\hline Value added & 1,000 Euros, deflated at 2004 prices & $20,746.710$ & $56,121.990$ \\
\hline Capital & $" n$ & $48,558.250$ & $272,734.300$ \\
\hline Intermediate inputs & $" "$ & $54,433.490$ & $417,053.300$ \\
\hline Gross operating margin (EBITDA) & $" "$ & $8,258.574$ & $42,748.430$ \\
\hline Share of females & & 0.236 & 0.221 \\
\hline Share of young workers & At most 29 years of age & 0.223 & 0.138 \\
\hline Share of prime-age workers & Between 30 and 49 years of age & 0.622 & 0.135 \\
\hline Share of older workers & Over 50 years of age & 0.155 & 0.119 \\
\hline Share of workers with low education & Below High-School Diploma (ISCED 1 and 2) & 0.357 & 0.319 \\
\hline Share of workers with medium education & High School Diploma (ISCED 3 and 4) & 0.404 & 0.281 \\
\hline Share of workers with high education & Over High-School Diploma (ISCED 5, 6, and 7) & 0.239 & 0.245 \\
\hline Share of managers & & 0.035 & 0.061 \\
\hline Share of professionals & & 0.094 & 0.168 \\
\hline Share of technicians and associate professionals & & 0.078 & 0.143 \\
\hline Share of clerks & & 0.167 & 0.190 \\
\hline Share of service workers and shop and market sales workers & & 0.033 & 0.126 \\
\hline Share of white-collar workers & & 0.407 & 0.310 \\
\hline Share of craft and related trades workers & & 0.258 & 0.324 \\
\hline Share of plant and machine operators and assemblers & & 0.236 & 0.310 \\
\hline Share of workers involved in elementary occupations & & 0.098 & 0.202 \\
\hline Share of blue-collar workers & & 0.593 & 0.310 \\
\hline Share of workers with fixed-term contracts & & 0.037 & 0.093 \\
\hline Share of part-time workers & Less that 30 hours per week & 0.100 & 0.125 \\
\hline Share of low-tenure workers & Less than 10 years of tenure & 0.208 & 0.162 \\
\hline
\end{tabular}

Source: SES-SBS data set (years: 1999-2007)

\section{Table 4: Sample summary statistics: sickness absenteeism}

\begin{tabular}{l|l|l|l}
\hline \hline Variable & Mean & Std. dev. & Observations \\
\hline \hline Rate of sickness absenteeism & 0.021 & 0.026 & 5,319 \\
\hline Rate of sickness absenteeism of low-tenure workers & 0.022 & 0.053 & 4,764 \\
Rate of sickness absenteeism of high-tenure workers & 0.021 & 0.029 & 4,764 \\
\hline Rate of sickness absenteeism of white-collar workers & 0.014 & 0.041 & 4,064 \\
Rate of sickness absenteeism of blue-collar workers & 0.026 & 0.034 & 4,064 \\
\hline Rate of sickness absenteeism in industrial firms & 0.021 & 0.023 & 3,885 \\
Rate of sickness absenteeism in non-industrial firms & 0.021 & 0.032 & 1,434 \\
\hline Rate of sickness absenteeism in low capital-intensive firms & 0.021 & 0.024 & 2,622 \\
Rate of sickness absenteeism in high capital-intensive firms & 0.022 & 0.027 & 2,618 \\
\hline Rate of sickness absenteeism in small- and medium-sized firms & 0.021 & 0.029 & 3,674 \\
Rate of sickness absenteeism in big firms & 0.023 & 0.017 & 1,544 \\
\hline \hline
\end{tabular}

Source: SES-SBS data set (years: 1999-2007)

Blue-collar workers include craft and related trades workers, plant and machine operators and assemblers, and workers involved in elementary occupations. White-collar workers include managers, professionals, technicians and associate professionals, clerks, and service workers and shop and market sales workers. We compute the rate of sickness absenteeism of blue- and white-collar workers only for firms that employ both categories of workers. High-tenure (low-tenure) workers are workers with 10 or more years (less than 10 years) of tenure. We compute the rate of sickness absenteeism of high-and low-tenure workers only for firms that employ both categories of workers. In both cases (i.e., analysis for blue- and whitecollar workers and high- and low-tenure workers), we also drop those observations that are left with no information on a contiguous year. For the different categories of firms (i.e., industrial versus non-industrial, etc.), we report statistics (and perform regressions) only on those observations that are in the same state for at least two consecutive years. Industrial firms include firms belonging to mining and quarrying, manufacturing, and construction sectors. Non-industrial firms include firms in the trade and services sectors. We classify low and high capital-intensive firms as those whose ratio between capital and labor (expressed in full-time equivalent employees) is below (above) the median. We define small- and medium-sized firms as those with less than 250 employees. Correspondingly, we define big firms as those with 250 or more employees. 
Table 5: The overall impact of sickness absenteeism on productivity

\begin{tabular}{|c|c|c|c|c|}
\hline \multicolumn{5}{|c|}{ Dependent variable: $y_{i t}$} \\
\hline Variable & OLS & FE & ACF & ACF-FE \\
\hline$l_{i t}$ & $\begin{array}{c}0.974^{* * *} \\
(0.025)\end{array}$ & $\begin{array}{c}0.903^{* * *} \\
(0.031)\end{array}$ & $\begin{array}{c}0.832^{* * *} \\
(0.037)\end{array}$ & $\begin{array}{c}0.794^{* * *} \\
(0.033)\end{array}$ \\
\hline$k_{t}$ & $\begin{array}{c}0.113^{* * *} \\
(0.014)\end{array}$ & $\begin{array}{c}0.066^{* * *} \\
(0.018)\end{array}$ & $\begin{array}{c}0.223^{* * *} * \\
(0.026)\end{array}$ & $\begin{array}{c}0.195^{* * *} \\
(0.028)\end{array}$ \\
\hline Rate of sickness absenteeism & $\begin{array}{l}-0.388 \\
(0.309)\end{array}$ & $\begin{array}{c}-0.450^{* * * *} \\
(0.171)\end{array}$ & $\begin{array}{c}-0.420^{*} \\
(0.247)\end{array}$ & $\begin{array}{c}-0.236^{* *} \\
(0.114)\end{array}$ \\
\hline Share of females & $\begin{array}{l}-0.111 \\
(0.078)\end{array}$ & $\begin{array}{c}-0.063 \\
(0.054)\end{array}$ & $\begin{array}{l}-0.057 \\
(0.038)\end{array}$ & $\begin{array}{c}-0.048 \\
(0.048)\end{array}$ \\
\hline Share of young workers & $\begin{array}{l}-0.196 \\
(0.131)\end{array}$ & $\begin{array}{c}0.085 \\
(0.070)\end{array}$ & $\begin{array}{c}-0.203^{* * *} \\
(0.066)\end{array}$ & $\begin{array}{c}0.045 \\
(0.058)\end{array}$ \\
\hline Share of prim-age workers & $\begin{array}{l}-0.137 \\
(0.121)\end{array}$ & $\begin{array}{c}0.038 \\
(0.057)\end{array}$ & $\begin{array}{l}-0.066 \\
(0.060)\end{array}$ & $\begin{array}{c}0.026 \\
(0.049)\end{array}$ \\
\hline Share of workers with low education & $\begin{array}{c}-0.313^{* * * *} \\
(0.083)\end{array}$ & $\begin{array}{l}-0.013 \\
(0.041)\end{array}$ & $\begin{array}{c}-0.117^{* *} \\
(0.053)\end{array}$ & $\begin{array}{l}-0.002 \\
(0.035)\end{array}$ \\
\hline Share of workers with medium education & $\begin{array}{c}-0.307 * * * \\
(0.080)\end{array}$ & $\begin{array}{l}-0.013 \\
(0.040)\end{array}$ & $\begin{array}{c}-0.109^{* *} \\
(0.053)\end{array}$ & $\begin{array}{l}-0.003 \\
(0.034)\end{array}$ \\
\hline Share of professionals & $\begin{array}{l}-0.259 \\
(0.211)\end{array}$ & $\begin{array}{l}-0.078 \\
(0.090)\end{array}$ & $\begin{array}{l}-0.045 \\
(0.124)\end{array}$ & $\begin{array}{l}-0.020 \\
(0.080)\end{array}$ \\
\hline Share of technicians and associate professionals & $\begin{array}{c}-0.679 * * * \\
(0.222)\end{array}$ & $\begin{array}{l}-0.058 \\
(0.096)\end{array}$ & $\begin{array}{c}-0.332^{* * *} \\
(0.127)\end{array}$ & $\begin{array}{l}-0.035 \\
(0.087)\end{array}$ \\
\hline Share of clerks & $\begin{array}{c}-0.500^{* *} \\
(0.214)\end{array}$ & $\begin{array}{l}-0.064 \\
(0.092)\end{array}$ & $\begin{array}{c}-0.295^{* *} \\
(0.122)\end{array}$ & $\begin{array}{l}-0.036 \\
(0.081)\end{array}$ \\
\hline Share of service workers and shop and market sales workers & $\begin{array}{c}-0.833^{* * *} \\
(0.244)\end{array}$ & $\begin{array}{c}0.050 \\
(0.103)\end{array}$ & $\begin{array}{c}-0.485^{* * *} \\
(0.140)\end{array}$ & $\begin{array}{c}0.067 \\
(0.092)\end{array}$ \\
\hline Share of craft and related trades workers & $\begin{array}{c}-0.882^{* * *} \\
(0.226)\end{array}$ & $\begin{array}{l}-0.102 \\
(0.104)\end{array}$ & $\begin{array}{c}-0.492^{* * *} \\
(0.120)\end{array}$ & $\begin{array}{l}-0.061 \\
(0.089)\end{array}$ \\
\hline Share of plant and machine operators and assemblers & $\begin{array}{c}-0.849 * * * \\
(0.230)\end{array}$ & $\begin{array}{l}-0.081 \\
(0.106)\end{array}$ & $\begin{array}{c}-0.544^{* * *} \\
(0.122)\end{array}$ & $\begin{array}{l}-0.046 \\
(0.089)\end{array}$ \\
\hline Share of workers involved in elementary occupations & $\begin{array}{c}-0.879 * * * \\
(0.235)\end{array}$ & $\begin{array}{l}-0.076 \\
(0.105)\end{array}$ & $\begin{array}{c}-0.503^{* * *} \\
(0.126)\end{array}$ & $\begin{array}{l}-0.038 \\
(0.091)\end{array}$ \\
\hline Share of workers with fixed term contracts & $\begin{array}{c}0.097 \\
(0.131)\end{array}$ & $\begin{array}{l}-0.023 \\
(0.059)\end{array}$ & $\begin{array}{c}0.054 \\
(0.080)\end{array}$ & $\begin{array}{l}-0.026 \\
(0.050)\end{array}$ \\
\hline Share of part-time workers & $\begin{array}{c}0.398^{* * *} \\
(0.091)\end{array}$ & $\begin{array}{c}0.056 \\
(0.056)\end{array}$ & $\begin{array}{c}0.344^{* * *} \\
(0.055)\end{array}$ & $\begin{array}{c}0.047 \\
(0.045)\end{array}$ \\
\hline Share of workers low-tenure workers & $\begin{array}{c}-0.165^{* *} \\
(0.068)\end{array}$ & $\begin{array}{c}0.093^{* *} \\
(0.040)\end{array}$ & $\begin{array}{c}-0.087^{*} \\
(0.044)\end{array}$ & $\begin{array}{l}0.061^{*} \\
(0.037)\end{array}$ \\
\hline High level of collective wage bargaining & $\begin{array}{c}0.134^{* * *} \\
(0.023)\end{array}$ & $\begin{array}{l}0.022^{*} \\
(0.012)\end{array}$ & $\begin{array}{c}0.093^{* * *} * \\
(0.013)\end{array}$ & $\begin{array}{c}0.018 \\
(0.011)\end{array}$ \\
\hline Old firm & $\begin{array}{c}0.001 \\
(0.039)\end{array}$ & $\begin{array}{c}0.026 \\
(0.027)\end{array}$ & $\begin{array}{l}-0.012 \\
(0.024)\end{array}$ & $\begin{array}{c}0.009 \\
(0.025)\end{array}$ \\
\hline Year dummies & yes & yes & yes & yes \\
\hline Size dummies & yes & yes & yes & yes \\
\hline Region dummies & yes & - & yes & - \\
\hline Industry dummies & yes & - & yes & - \\
\hline Firm fixed effects & no & yes & no & yes \\
\hline
\end{tabular}

Source: SBS-SES data set (years: 1999-2007)

Standard errors in parentheses. We compute robust standard errors for OLS and FE, and bootstrap standard errors for ACF and ACF-FE. ***, **, and * denote, respectively, the 1\%, 5\%, and 10\% significance level. The reference group for the age distribution is the share of older workers; for the education distribution, it is the share of workers with high education; for the occupation distribution, it is the share of managers. 'Old firm' is a dummy variable indicating that the firm is at least 10 years old. Size dummies consist of 3 dummies, 1 for each size class as of Table 2; region dummies consist of 3 dummies, 1 for each administrative region in Belgium (Brussels-Capital, Flanders, and Walloon); industry dummies account for 146 dummies, 1 for each 3-digit NACE Rev 1.1 industry. 


\section{Table 6: The impact depending on the categories of workers}

\begin{tabular}{llr}
\hline \hline Rate of sickness absenteeism of low-tenure workers & 0.006 & $(0.052)$ \\
Rate of sickness absenteeism of high-tenure workers & $-0.479^{* * *}$ & $(0.087)$ \\
\hline \multicolumn{2}{l}{ Observations: 4,764 } \\
\hline \hline Rate of sickness absenteeism of white-collar workers & -0.022 & $(0.087)$ \\
Rate of sickness absenteeism of blue-collar workers & $-0.247^{* * *}$ & $(0.083)$ \\
\hline \multicolumn{2}{c}{ Observations: 4,064 } \\
\hline \hline
\end{tabular}

Source: SBS-SES data set (years: 1999-2007)

Estimation method: ACF-FE. These estimates include the same set of controls in Table 5. For the rest, see the footnotes of Table 5 and Table 4.

\section{Table 7: The impact depending on the categories of firms}

\begin{tabular}{|c|c|c|c|}
\hline \multicolumn{4}{|l|}{ Industrial firms versus non-industrial firms } \\
\hline Impact of sickness absenteeism on industrial firms & $-0.288^{* * *}$ & $(0.107)$ & {$[3,885]$} \\
\hline Impact of sickness absenteeism on non-industrial firms & -0.026 & $(0.633)$ & {$[1,434]$} \\
\hline \multicolumn{4}{|c|}{ Low capital-intensive firms versus high capital-intensive firms } \\
\hline Impact of sickness absenteeism on low capital-intensive firms & 0.057 & $(0.214)$ & {$[2,622]$} \\
\hline Impact of sickness absenteeism on high capital-intensive firms & $-0.683^{* * *}$ & $(0.223)$ & {$[2,618]$} \\
\hline \multicolumn{4}{|c|}{ Small- and medium-sized firms versus big firms } \\
\hline Impact of sickness absenteeism on small- and medium-sized firms & $-0.328^{* *}$ & $(0.161)$ & {$[3,674]$} \\
\hline Impact of sickness absenteeism on big firms & 0.001 & $(0.620)$ & {$[1,544]$} \\
\hline
\end{tabular}

Source: SBS-SES data set (years: 1999-2007)

Estimation method: ACF-FE. In square brackets, we report the number of observations. These estimates include the same set of controls in Table 5. For the rest, see the footnotes of Table 5 and Table 4. 


\section{References}

Ackerberg, D. A., Caves, K., Frazer, G., 2015. Identification Properties of Recent Production Function Estimators. Econometrica 83 (6), 2411-2451.

Allen, S. G., 1983. How Much Does Absenteeism Cost? The Journal of Human Resources $18(3), 379-393$.

Coles, M., Lanfranchi, J., Treble, J., 2007. Pay, Technology, and the Cost of Worker Absence. Economic Inquiry 45 (2), 268-285.

Demunter, C., 2000. Structure and Distribution of Earnings Durvey: Analysis 1995, Statistics Belgium Working Paper.

Devicienti, F., Grinza, E., Vannoni, D., 2018. The Impact of Part-Time Work on Firm Productivity: Evidence from Italy. Industrial and Corporate Change 27 (2), 321-347.

Dionne, G., Dostie, B., 2007. New Evidence on the Determinants of Absenteeism Using Linked Employer-Employee Data. Industrial \& Labor Relations Review 61 (1), 108-120.

Giuliano, R., Mahy, B., Kampelmann, S., Rycx, F., 2017. Short Notice, Big Difference? The Effect of Temporary Employment on Firm Competitiveness Across Sectors. British Journal of Industrial Relations 55 (2), 421-449.

Grant, R. M., 1996. Toward a Knowledge-Based Theory of the Firm. Strategic Management Journal 17 (S2), 109-122.

Herrmann, M. A., Rockoff, J. E., 2012. Worker Absence and Productivity: Evidence from Teaching. Journal of Labor Economics 30 (4), 749-782.

Heywood, J. S., Jirjahn, U., Wei, X., 2008. Teamwork, Monitoring and Absence. Journal of Economic Behavior \& Organization 68 (3), 676-690.

Ichino, A., Riphahn, R. T., 2005. The Effect of Employment Protection on Worker Effort: Absenteeism during and after Probation. Journal of the European Economic Association $3(1), 120-143$.

Levinsohn, J., Petrin, A., 2003. Estimating Production Functions Using Inputs to Control for Unobservables. The Review of Economic Studies 70 (2), 317-341.

Markussen, S., Røed, K., Røgeberg, O. J., Gaure, S., 2011. The Anatomy of Absenteeism. Journal of Health Economics 30 (2), 277-292. 
Miller, R., Murnane, R. J., Willett, J. B., 2008. Do Worker Absences Affect Productivity? The Case of Teachers. International Labour Review 147 (1), 71-89.

Mion, G., Opromolla, L. D., 2014. Managers' Mobility, Trade Performance, and Wages. Journal of International Economics 94 (1), 85-101.

Nicholson, S., Pauly, M. V., Polsky, D., Shardad, C., Szrekb, H., Bergerd, M. L., 2006. Measuring the Effects of Work Loss on Productivity with Team Production. Health Economics $15(2), 111-123$.

Nonaka, I., 1994. A Dynamic Theory of Organizational Knowledge Creation. Organization Science 5 (1), 14-37.

OECD (Ed.), 2009. Measuring Capital. OECD Organisation for Economic Co-operation and Development, Paris.

Olley, S. G., Pakes, A., 1996. The Dynamics of Productivity in the Telecommunications Equipment Industry. Econometrica 64 (6), 1263-1297.

Pauly, M. V., Nicholson, S., Polsky, D., Berger, Marc L, S. C., 2008. Valuing Reductions in Onthe-Job Illness: Presenteeism from Managerial and Economic Perspectives. Health Economics 17 (4), 469-485.

Pauly, M. V., Nicholson, S., Xu, J., Polsky, D., Danzon, P. M., 2002. A General Model of the Impact of Absenteeism on Employers and Employees. Health Economics 11 (3), 221-231.

Van Biesebroeck, J., 2007. Robustness of Productivity Estimates. The Journal of Industrial Economics 55 (3), 529-569.

Vandenberghe, V., 2012. Are firms willing to employ a greying and feminizing workforce? Labour Economics 22 (1), 30-46.

Vandenberghe, V., Rigo, M., Waltenberg, F., 2013. Ageing and Employability. Evidence from Belgian Firm-level Data. Journal of Productivity Analysis 40 (1), 111-136.

Zhang, W., Woodcock, S., Anis, A. H., 2017. Valuing Productivity Loss due to Absenteeism: Firm-Level Evidence from a Canadian Linked Employer-Employee Survey. Health Economics Review 7 (3). 


\section{Appendices}

\section{A. The empirical framework and the ACF and ACF-FE methods}

As specified in Section 3, the estimating equation is:

$$
y_{i t}=\alpha+\beta_{l} l_{i t}+\beta_{k} k_{i t}+\theta S A B S_{i t}+\gamma F_{i t}+\omega_{i t}+\epsilon_{i t} .
$$

We assume that the unobserved productivity level, $\omega_{i t}$, evolves following a first-order Markov process; that the firm observes its realization at $t$ in the same period, at $t$; and the firm can at least partially anticipate it. Hence, we can write:

$$
E\left[\omega_{i t} \mid I_{i t-1}\right]=g\left(\omega_{i t-1}\right) \quad \text { and } \quad \omega_{i t}=g\left(\omega_{i t-1}\right)+\xi_{i t},
$$

where: $I_{i t-1}$ is the information set of firm $i$ at time $t-1 ; g(\cdot)$ is a general function, and $g\left(\omega_{i t-1}\right)$ is the part of $\omega_{i t}$ that the firm can predict at $t-1$; and $\xi_{i t}$ is the innovation in $\omega_{i t}$, which the firm observes at $t$ and, by construction, cannot predict at $t-1$ (i.e., $E\left[\xi_{i t} \mid I_{i t-1}\right]=0$ ). In practice, firms observe $\omega_{i t}$ at $t$ and construct expectations on $\omega_{i t}$ at $t-1$ by using $g(\cdot)$.

We assume that capital is non-perfectly variable. This implies that the firm decides upon the level of capital to use at $t$ one period earlier, at $t-1$. This assumption entails that there are adjustment costs of capital. It accounts for the fact that new capital takes time to be ordered, delivered, installed, and put into operation. Conversely, we assume that labor is perfectly variable. This implies that the firm decides upon the level of labor to use at $t$ in the same period, at $t$. We assume that sickness absenteeism at $t$ is also determined at $t$. This is consistent with the idea that employees' health, and thus sickness absenteeism, can respond immediately to productivity shocks/unobserved variables.

We further assume that intermediate inputs are perfectly variable; that the firm's demand for intermediate inputs, $m_{i t}$, is a function of labor, capital, sickness absenteeism, and the firm's unobserved productivity level; and that this function is strictly increasing in $\omega_{i t}$ :

$$
m_{i t}=f\left(l_{i t}, k_{i t}, S A B S_{i t}, \stackrel{+}{\omega}_{i t}\right) .
$$

Intuitively, this means that the higher the unobserved productivity level, the larger the demand for intermediate inputs is to be. If this (strict) monotonicity assumption holds, $f$ can be inverted out to deliver an expression of $\omega_{i t}$ as a function of $l_{i t}, k_{i t}, S A B S_{i t}$, and $m_{i t}$, which are observable:

$$
\omega_{i t}=f^{-1}\left(l_{i t}, k_{i t}, S A B S_{i t}, m_{i t}\right) .
$$


This expression for $\omega_{i t}$ can then be substituted into Equation (A.1). This brings:

$$
y_{i t}=\alpha+\beta_{l} l_{i t}+\beta_{k} k_{i t}+\theta S A B S_{i t}+\gamma F_{i t}+f^{-1}\left(l_{i t}, k_{i t}, S A B S_{i t}, m_{i t}\right)+\epsilon_{i t} .
$$

At this point, ACF introduce a two-step method to recover estimates of $\beta_{l}, \beta_{k}$, and $\theta$ (and $\gamma$ ). In the first step, $y_{i t}$ is nonparametrically regressed against a function in $l_{i t}, k_{i t}, S A B S_{i t}$, $m_{i t}$, and $F_{i t}$, referred to as $\Phi\left(l_{i t}, k_{i t}, S A B S_{i t}, m_{i t}, F_{i t}\right) .{ }^{\text {A.1 }}$ From this regression, it is possible to identify the composite term:

$$
\widehat{\Phi}_{i t}^{*}=\alpha+\beta_{l} l_{i t}+\beta_{k} \widehat{k_{i t}+} \theta S A B S_{i t}+\omega_{i t} .
$$

These are just the predicted values of $y_{i t}$ from the regression minus the estimated $\hat{\gamma} F_{i t}$. Given guesses of $\beta_{l}, \beta_{k}$, and $\theta$, respectively denoted with $\beta_{l}^{*}, \beta_{k}^{*}$, and $\theta^{*}$, it is possible to recover implied $\omega_{i t}, \hat{\omega}_{i t}\left(\beta_{l}^{*}, \beta_{k}^{*}, \theta^{*}\right)^{\mathrm{A} .2}$, as:

$$
\hat{\omega}_{i t}\left(\beta_{l}^{*}, \beta_{k}^{*}, \theta^{*}\right)=\widehat{\Phi}_{i t}^{*}-\beta_{l}^{*} l_{i t}-\beta_{k}^{*} k_{i t}-\theta^{*} S A B S_{i t}
$$

Recalling that $\omega_{i t}$ is assumed to follows a first-order Markov process (i.e., $\left.\omega_{i t}=g\left(\omega_{i t-1}\right)+\xi_{i t}\right)$ and given $\hat{\omega}_{i t}\left(\beta_{l}^{*}, \beta_{k}^{*}, \theta^{*}\right)$, it is possible to compute the implied innovations, $\hat{\xi}_{i t}\left(\beta_{l}^{*}, \beta_{k}^{*}, \theta^{*}\right)$, as the residuals from a nonparametric regression of $\hat{\omega}_{i t}\left(\beta_{l}^{*}, \beta_{k}^{*}, \theta^{*}\right)$ on $\hat{\omega}_{i t-1}\left(\beta_{l}^{*}, \beta_{k}^{*}, \theta^{*}\right)$. A.3 The second step evaluates the sample analogues of the moment conditions ${ }^{\text {A.4 }}$ imposed by the model:

$$
\begin{aligned}
& \frac{1}{N} \frac{1}{T} \sum_{i} \sum_{t} \hat{\xi}_{i t}\left(\beta_{l}^{*}, \beta_{k}^{*}, \theta^{*}\right) k_{i t}=0 \\
& \frac{1}{N} \frac{1}{T} \sum_{i} \sum_{t} \hat{\xi}_{i t}\left(\beta_{l}^{*}, \beta_{k}^{*}, \theta^{*}\right) l_{i t-1}=0 \\
& \frac{1}{N} \frac{1}{T} \sum_{i} \sum_{t} \hat{\xi}_{i t}\left(\beta_{l}^{*}, \beta_{k}^{*}, \theta^{*}\right) S A B S_{i t-1}=0
\end{aligned}
$$

The search over $\beta_{l}^{*}, \beta_{k}^{*}$, and $\theta^{*}$ continues until $\hat{\beta}_{l}, \hat{\beta}_{k}$, and $\hat{\theta}$ are found that satisfy Equation (A.3). These are the ACF estimates of $\beta_{l}, \beta_{k}$, and $\theta$.

The ACF-FE method only modifies the first stage of the ACF procedure. Here, TFP

\footnotetext{
${ }^{\text {A.1 }}$ We approximate $\Phi(\cdot)$ with a third-order polynomial in $l_{i t}, k_{i t}, S A B S_{i t}$, and $m_{i t}$, with $F_{i t}$ added linearly. A.2 They also include the constant term $\alpha$, which ends up not mattering.

${ }^{\text {A. }} 3$ We approximate $g(\cdot)$ with a third-order polynomial in $\hat{\omega}_{i t-1}\left(\beta_{l}^{*}, \beta_{k}^{*}, \theta^{*}\right)$.

${ }^{\text {A. }}{ }^{4}$ Since we assume that capital is non-perfectly variable, labor is perfectly variably, and sickness absenteeism at $t$ is determined at $t$, they are: $E\left[\xi_{i t} k_{i t}\right]=0, E\left[\xi_{i t} l_{i t-1}\right]=0$, and $E\left[\xi_{i t} S A B S_{i t-1}\right]=0$.
} 
explicitly accounts for firm fixed effects and is modeled as:

$$
A_{i t}=\exp \left\{\alpha+\theta S A B S_{i t}+\gamma F_{i t}+\eta_{i}+\omega_{i t}^{*}+\epsilon_{i t}\right\}
$$

The firm's unobserved productivity level $\omega_{i t}$ is now split into $\eta_{i}$, the time-invariant part, and $\omega_{i t}^{*}$, the time-varying part. The estimating production function is then:

$$
y_{i t}=\alpha+\beta_{l} l_{i t}+\beta_{k} k_{i t}+\theta S A B S_{i t}+\gamma F_{i t}+\eta_{i}+\omega_{i t}^{*}+\epsilon_{i t} .
$$

We assume that the firm's demand for intermediate inputs depends on the levels of labor and capital inputs, sickness absenteeism, and $\omega_{i t}^{*}$. We thus exclude that it also depends on $\eta_{i}$. This assumption implies that the demand for intermediate inputs, which are assumed perfectly variable, depends only on time-varying components. Hence, Equation (A.2) here is:

$$
y_{i t}=\alpha+\beta_{l} l_{i t}+\beta_{k} k_{i t}+\theta S A B S_{i t}+\gamma F_{i t}+\eta_{i}+f^{-1}\left(l_{i t}, k_{i t}, S A B S_{i t}, m_{i t}\right)+\epsilon_{i t} .
$$

As before, by setting:

$$
\Phi\left(l_{i t}, k_{i t}, S A B S_{i t}, m_{i t}, F_{i t}\right) \equiv \alpha+\beta_{l} l_{i t}+\beta_{k} k_{i t}+\theta S A B S_{i t}+\gamma F_{i t}+f^{-1}\left(l_{i t}, k_{i t}, S A B S_{i t}, m_{i t}\right),
$$

it is possible to write Equation (A.4) as:

$$
y_{i t}=\Phi\left(l_{i t}, k_{i t}, S A B S_{i t}, m_{i t}, F_{i t}\right)+\eta_{i}+\epsilon_{i t} .
$$

The ACF-FE method now performs nonparametric FE estimation to remove $\eta_{i}$. It is then possible to obtain an estimate of $\Phi(\cdot)$ that explicitly removes firm fixed effects, and proceed to the second stage of the estimation procedure (unchanged with respect to the ACF method) from:

$$
\widehat{\Phi}_{i t}^{*}=\alpha+\beta_{l} l_{i t}+\beta_{k} \widehat{k i t} \theta S A B S_{i t}+\omega_{i t}^{*}
$$


DEPARTMENT OF ECONOMICS AND STATISTICS

UNIVERSITY OF TORINO

Corso Unione Sovietica 218 bis - 10134 Torino (ITALY)

Web page: http://esomas.econ.unito.it/ 